\title{
Cidade Inteligente e Cidadãos Participativos - Uma Proposta de Transformação Contínua da Cidade Através da Ação Colaborativa dos Cidadãos
}

\author{
Smart City and Participating Citizens - A Proposal for Continuous \\ Transformation of the City Through Citizen's Collaborative Action \\ Ciudad inteligente y ciudadanos participativos - Una propuesta de \\ transformación continuada de la ciudad por medio de la acción de \\ colaboración de los ciudadanos
}
Ville intelligente et citoyens participants - Une proposition de transformation continue de la ville par l'action colaborative des citoyens

Alexsandro Amarante alexamarante@unifor.com Universidade de Fortaleza

\section{Resumo}

O tema Cidades Inteligentes está se tornando cada vez mais comum por envolver diversas áreas profissionais tais como: Tecnologia da informação, Arquitetura e urbanismo, Engenharia civil, Engenharia ambiental, Engenharia elétrica, Economia e Administração privada e pública. Porém cidades são agregados de pessoas, as quais, segundo Howard Gardner, possuem múltiplas inteligências. Seguindo essa linha de pensamento, é possível supor que cidades também possuem inteligências múltiplas? Como os cidadãos podem colaborar para definir projetos que visem tornar suas cidades mais inteligentes?

Palavras-chave: Cidade Inteligente. Inteligências Múltiplas. Planejamento Urbano. Engenharia. Tecnologia da Informação. Ação Colaborativa dos Cidadãos.

\begin{abstract}
The Smart Cities theme is becoming increasingly common as it involves a number of professional areas such as information technology, architecture and urban planning, civil engineering, environmental engineering, electrical engineering, economics, and private and public administration. However cities are aggregates of people, and people according to Howard Gardner have multiple intelligences according to this line of thinking, is it possible to assume that cities also have multiple intelligences? How can citizens collaborate to define projects that make their cities smarter?
\end{abstract}

Keywords: Smart City, Multiplicity of Intelligences. Urban planning. Engineering. Information technology. Citizen's Collaborative Action.

\section{Resumen}

El tema Ciudades Inteligentes está cada día más común, una vez que envuelve distintas áreas profesionales como tecnología de la información, arquitectura y urbanismo, ingeniería civil, ingeniería ambiental, ingeniería eléctrica, economía y administración pública y privada. Sin embargo, ciudades son agregados de personas y personas, según Howard Gardner, poseen inteligencias múltiples. Siguiendo esta línea de pensamiento, ¿es posible suponer que ciudades también poseen inteligencias múltiples? ¿Cómo los ciudadanos pueden colaborar para definir proyectos que objetiven hacer sus ciudades más inteligentes.

Palabras clave: Ciudad Inteligente, Inteligencias Múltiples. Planificación Urbana. Ingeniería. Tecnología de la Información. Acción Colaborativa de los ciudadanos. 


\begin{abstract}
Résumé:
Le thème Villes Intelligentes est, de plus en plus, courant car il implique plusieurs domaines professionnels tels que la technologie de l'information, l'architecture, l'urbanisme, la génie civil, la génie électrique, la génie de l'environnement, l'économie, l'administration publique et l'administration privée. Pourtant, le villes sont des agrégats de gens, et des gens, selon Howard Gardner, ont des intelligences multiples. Dans cette ligne de pensée, est-il possible de supposer que les villes ont, aussi, des intelligences multiples? Comment les citoyens peuvent-ils collaborer pour définir des projets qui rendent leurs villes plus intelligentes?.
\end{abstract}

Mots-clés: Ville intelligente. Intelligences multiples. Urbanisme. Ingénierie. Technologie de l'information. Action collaborative des citoyens.

\title{
1 Introdução
}

Apesar da expressão "cidades inteligentes" estar se tornando comum na mídia e em discussões de áreas profissionais tão variadas quanto Tecnologia da Informação e Comunicação, Arquitetura e Urbanismo, Engenharia Civil, Ambiental, Sanitária, de Tráfego e Elétrica, e até mesmo para o cidadão comum, percebe-se que cada pessoa tende a um entendimento alinhado especialmente com sua área de formação ou de conhecimento.

É possível que isso ocorra como uma manifestação do pensamento de Howard Gardner sobre inteligências múltiplas? E se for o caso, pode-se dizer que as diversas definições seriam aspectos de diferentes tipos de inteligência relacionadas com a dimensão do coletivo de uma cidade? E esse coletivo, formado pelos seus cidadãos, pode colaborar de forma simples, efetiva e prática com o processo de tornar a cidade, ou comunidade, mais inteligente?

O objetivo geral do presente artigo é sugerir critérios, baseados nas múltiplas inteligências propostas por Howard Gardner, para que os cidadãos colaborem na priorização de projetos para tornar suas cidades (ou comunidades) mais inteligentes.

Para esse fim, serão pesquisados os diversos entendimentos do conceito de cidades inteligentes e as múltiplas inteligências propostas por Gardner; sugerido um relacionamento entre as múltiplas inteligências pessoais e as características de uma cidade inteligente para, nesse contexto coletivo de cidades, propor um método de priorização, segundo a ótica do cidadão, das inteligências da cidade, visando auxiliar a seleção de projetos e programas públicos, assim como de iniciativas privadas, em um processo contínuo de transformação do estágio atual de uma cidade em um contexto mais inteligente.

Para tanto, tem-se os seguintes objetivos específicos:

- Pesquisar o conceito de múltiplas inteligências e o significado de cada tipo de inteligência proposta;

- Pesquisar as diferentes definições de cidades inteligentes;

- Realizar entrevista com profissionais de diferentes formações sobre quais temas deveriam ser priorizados para considerar sua cidade mais inteligente; $\mathrm{e}$

- Propor uma metodologia de seleção e priorização de projetos (alinhados com as demandas dos cidadãos) para tornar a cidade mais inteligente, visando orientar os gestores públicos e as instituições privadas na priorização de projetos e programas.

A estrutura do presente artigo exibe no primeiro tópico a justificativa e a introdução do mesmo.

O segundo tópico aborda o conceito de inteligências múltiplas e identifica o significado de cada tipo.

$\mathrm{O}$ tema cidades inteligentes será discorrido no seguinte, em especial buscando identificar diferentes definições em textos, opiniões de profissionais e estudantes, e apresentações inclusive em vídeos na internet.

Apresentar-se-á na última parte a proposta de transformação contínua da cidade, visando torná-la continuamente mais inteligente a partir de um processo colaborativo de seus cidadãos.

No quinto e último tópico serão apresentadas as considerações finais. 


\section{Inteligências Múltiplas}

Em 1983, o psicólogo e professor de Harvard, Howard Gardner ao coordenar uma equipe de pesquisadores sugeriu que as pessoas possuiriam diversas competências intelectuais e independentes entre si, que chamou de estruturas da mente, competências intelectuais ou inteligências, sendo a teoria proposta denominada de teoria das inteligências múltiplas (GARDNER, 1983).

Segundo Soares (2014), "a palavra inteligência traduz a faculdade de entender, pensar, raciocinar e interpretar", explicando que, para Gardner, as competências individuais demandam instituições sociais, sendo ainda influenciadas pela época, local e cultura da estrutura social na qual se encontra.

A formulação do conceito de múltiplas inteligências em um mesmo indivíduo rompe as barreiras do entendimento histórico, fortemente associado à habilidade lógico-matemática ou linguística, tendo em vista que a teoria das múltiplas inteligências associa o uso das habilidades para resolver problemas e criar respostas que a sociedade desse indivíduo valoriza (MATIAS, 2010).

Para Zandomeneghi (2005), Gardner usou evidências antropológicas e biológicas em sua pesquisa, apresentando oito critérios para a definição de inteligência:

- Isolamento potencial por dano cerebral;

- A existência de prodígios e outros indivíduos excepcionais;

- Um conjunto operações identificáveis;

- Uma história de desenvolvimento distintiva, alinhada a um conjunto definível de desempenhos proficientes de expert "estado final";

- Uma história evolutiva e a plausivelmente evolutiva;

- Apoio de tarefas psicológicas experimentais;

- Apoio de achados psicométricos;

- Suscetibilidade à codificação em um sistema simbólico.

Como resultado, na ocasião, chegou-se a mapear sete inteligências (Figura 01):

- Inteligência linguística;

- Inteligência musical;

- Inteligência lógico-matemática;

- Inteligência espacial;

- Inteligência corporal-cinestésica;

- Inteligência intrapessoal;

- Inteligência interpessoal.

Posteriormente, Gardner acresceu duas inteligências adicionais:

- Inteligência naturalista;

- Inteligência existencial.

Por fim (BIG THINK, 2016), em um depoimento disponível em vídeo na internet, Gardner afirma que está considerando acrescer uma inteligência associada ao êxito no ensino (teaching-pedagogical intelligence), e descarta outras, como humorística, gastronômica e sexual (humour, cooking and sexual intelligence). 
Figura 01: Sete inteligências iniciais e as duas inteligências posteriormente propostas por Gardner

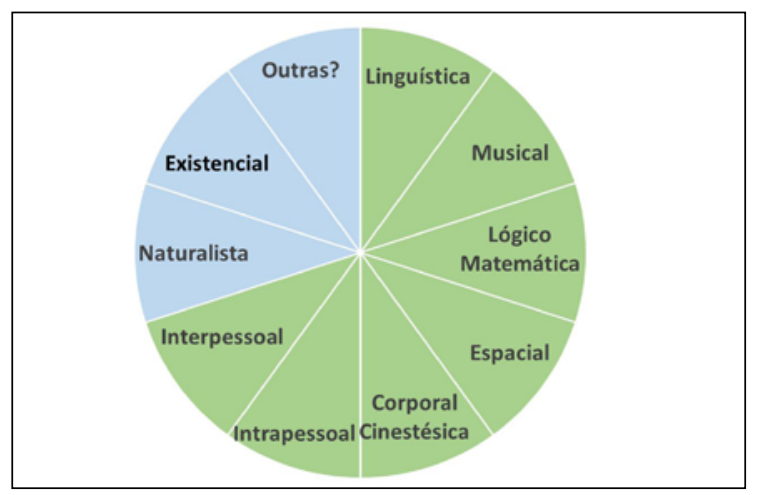

Fonte: Autor

A seguir, apresentar-se-á um resumo das inteligências citadas anteriormente.

\subsection{As sete inteligências inicialmente propostas}

Conforme Zandomeneghi (2005), pode-se compreender as sete inteligências inicialmente propostas no estudo coordenado por Gardner como segue:

\section{a) Linguística}

Habilita o indivíduo a descrever, narrar, observar, comparar, relatar, avaliar, concluir e sintetizar. Essa inteligência seria facilmente observável em profissionais como advogados, jornalistas, escritores e poetas, por exemplo. Gardner (1983 apud Zandomeneghi, 2005), destaca ainda que, para a sociedade ocidental, existem outras habilidades decorrentes dessa inteligência, como a retórica, o potencial mnemônico, a explicação e própria reflexão sobre a linguagem.

\section{b) Musical}

Habilita a identificar diferentes sons e suas nuances quanto à intensidade e direcionalidade, reconhecer sons naturais e perceber a distinção entre tom, melodia, ritmo, timbre e frequência, isolando sons em agrupamentos musicais. Os profissionais nos quais se observa facilmente essa inteligência são os poetas, compositores e músicos.

\section{c) Lógico-matemática}

Caracterizada por duas habilidades básicas, sendo a primeira a memória para guardar etapas de uma cadeia de raciocínio, e a segunda habilidade o reconhecimento da origem das ligações entre as diversas proposições. Indivíduos com essa inteligência em destaque têm facilidade de compreender e realizar cálculos, geometria espacial e problemas lógicos. Observa-se essa inteligência em atividades de lazer de quem tem preferência por jogos como palavras cruzadas e xadrez, por exemplo. Os profissionais em que se observa o uso dessa inteligência habitualmente são engenheiros, arquitetos, físicos e matemáticos.

\section{d) Espacial}

Habilita a percepção de formas e objetos em ângulos diversos, incluindo: ter uma compreensão espacial do mundo visual com precisão; efetuar transformações sobre as percepções, ; imaginar movimentos ou o deslocamento interno entre partes; recriar aspectos da experiência visual e perceber as direções no espaço concreto e abstrato, e no tempo. Observa-se essa inteligência destacada em profissionais como geógrafos, exploradores e marinheiros, por exemplo.

\section{e) Corporal-cinestésica}

Habilita o indivíduo a movimentar seu corpo de maneira diferenciada e hábil, e capacidade de trabalhar com objetos. Essa inteligência se destaca em mímicos, bailarinos, cirurgiões, atletas e contorcionistas. 


\section{f) Intrapessoal}

Refere-se à habilidade de ver a si mesmo no seu contexto de vida de forma equilibrada, manifestando-se em qualidades como autoestima e automotivação. Essa inteligência seria empregada para promover a construção da felicidade pessoal e social. Os indivíduos que atuam como conselheiros, religiosos, políticos e psicólogos são exemplos de possíveis portadores de um grau mais elevado dessa inteligência.

\section{g) Interpessoal}

Por sua vez, a inteligência interpessoal se refere à capacidade de compreender intenções, motivações e desejos não verbalizados de outras pessoas. Como resultado, seria a fonte da qualidade conhecida como empatia. Como exemplo pode-se citar líderes religiosos, filósofos, terapeutas e políticos.

\subsection{As duas inteligências propostas posteriormente}

Nicollier (2005) explica a inteligência naturalista como uma habilidade relacionada a: identificar padrões na natureza; classificar objetos naturais e suas espécies; analisar e entender relações sistêmicas no meio ambiente (naturalmente evoluídos ou estimulados através de interferências do ser humano), assim como fenômenos naturais. Observa-se essa inteligência mais destacada em fazendeiros, botânicos, biólogos e paisagistas, por exemplo.

Matias (2010) cita que Gardner publicou, em 1999, suas inquietações sobre outras duas inteligências, além da naturalista, que seriam a espiritual e existencial. Porém, na ocasião, elegeu apenas a naturalista para compor a lista original. Posteriormente optou por abandonar a expressão "inteligência espiritual" substituindo-a por "inteligência existencial", que seria a capacidade de observar as questões chamadas fundamentais da existência, refletindo e ponderando sobre as mesmas. Líderes religiosos e pensadores filosóficos seriam exemplos de pessoas com essa inteligência com maior predominância.

\section{Cidades Inteligentes - Smart Cities}

É comum se observar definições de cidades inteligentes associadas ao uso de tecnologias da informação e comunicação. Para a instituição Future Learn - The Open University, cidade inteligente é uma expressão que descreve o uso de tecnologias inteligentes e informações como a forma de resolver os desafios de sustentabilidade em uma cidade (OPEN UNIVERSITY, 2016a).

O mesmo conceito pode ser observado na definição do European Commision (2015), para o qual as tecnologias digitais se traduzem em melhores serviços públicos para os cidadãos nas cidades inteligentes, melhor uso dos recursos naturais e menor impacto no meio ambiente.

Por sua vez, Komininos (2008) parece avançar esse entendimento para além das tecnologias quando explica que regiões, comunidades e cidades inteligentes criam o ambiente apropriado para aprimorar as habilidades cognitivas, de aprendizado e inovação de seus habitantes. Esse contexto cria um desafio para o surgimento de um ambiente de colaboração no qual a coletividade propõe incontáveis combinações de habilidades individuais e sistemas de informações que operam de forma criativa em espaços reais e digitais das cidades.

Segundo Lindskog (2016) para o California Institute for Smart Communities uma comunidade inteligente é aquela na qual o seu governo e cidadãos entendem o potencial das tecnologias de informação e comunicação, e tomam decisões conscientes em seus usos para transformar a vida e o trabalho de forma significativa e positiva em sua região.

Observa-se que, para algumas, as definições do termo "cidade inteligente" poderiam ser facilmente reduzidas à "cidade digital", restringindo-se aos aspectos de tecnologias de informação e comunicação, aplicações eletrônicas e digitais. Enquanto, em para outros, torna-se mais abrangente e não exclusivamente dependente de tecnologias de informação e comunicação.

O Intelligent Community Forum (ICF, 2016) é uma organização que representa uma rede global de cidades e regiões que congregam diversos especialistas, de diferentes áreas, cujo objetivo é auxiliar comunidades a empregarem as tecnologias de informação e comunicação para criar desenvolvimento e prosperidade inclusiva, enfrentar os desafios sociais e de governança, e enriquecer sua qualidade de vida.

Em um estudo realizado na província de Ontário, Canadá, o ICF definiu fatores críticos de sucesso para a criação de comunidades inteligentes, a Intelligent Community Indicators, visando disponibilizar uma primeira estrutura conceitual para entender todos os fatores que determinam a competitividade de uma comunidade em uma economia de banda larga: 
(1) Broadband: Disponibilidade de banda larga para organizações e cidadãos;

(2) Knowledge Workforce: Força de trabalho (educação, treinamento e profissionais) capaz de atividades associadas à economia do conhecimento;

(3) Innovation: Incentivo à inovação nos setores público e privado, criação de agrupamentos econômicos criativos e compartilhados, e capital de risco;

(4) Digital Equality: Políticas e programas incentivadores da democracia digital e redução da exclusão digital, para organizações e cidadãos dos mais variados tipos;

(5) Sustainability: Ações e estímulos à melhoria dos padrões de vida atuais, enquanto se mantém a capacidade das futuras gerações de fazer o mesmo; e

(6) Advocacy: Habilidade da comunidade para envolver seus líderes e cidadãos, indivíduos empreendedores e instituições na compreensão dos desafios e oportunidades, trabalhando em conjunto para construir uma visão unificadora de futuro comum.

Para Komininos (2008), a evolução das cidades inteligentes resulta de uma forte integração das seguintes dimensões da inteligência:

(1) Inteligência humana individual;

(2) Inteligência humana coletiva e

(3) Inteligência artificial.

A inteligência humana individual se refere à inteligência, inventividade e criatividade de cada indivíduo que habita e/ou trabalha na cidade, como cientistas, artistas, empresários, professores, empreendedores e investidores, gerando uma cidade criativa, e impactando e sendo impactados pela organização do espaço e condições de trabalho.

A inteligência humana coletiva se refere à capacidade de interação e colaboração para decidir sobre seu futuro, criar soluções para a coletividade, inovar e inventar em conjunto, o que exige instituições e organização da cidade para estimular a cooperação do conhecimento entre os cidadãos.

Por sua vez, a inteligência artificial contempla as condições de infraestrutura de comunicação, o ambiente físico propício, a digitalização de informações da estrutura e da funcionalidade da cidade disponibilizadas aos cidadãos.

Dessa forma, para Komininos (2016), todas as cidades inteligentes exigem uma cidade digitalizada, porém nem todas as cidades digitais são, obrigatoriamente, cidades inteligentes.

Diversas iniciativas surgem nesse contexto de múltiplas dimensões para classificação de cidades, como o Programa das Nações Unidades para Assentamentos Humanos (ONU-Habitat), em que foi lançado na Itália, em setembro de 2016, durante o sexto Fórum Urbano Mundial, um indicador para avaliar o progresso de municípios (EXAME, 2016): o Índice de Prosperidade da Cidade (CPI).

Esse indicador propõe avaliar cinco áreas consideradas essenciais pela ONU:

(1) Produtividade;

(2) Infraestrutura;

(3) Igualdade;

(4) Qualidade de vida e

(5) Sustentabilidade ambiental.

O CPI visa auxiliar os gestores no processo de identificação de áreas com maior potencial de desenvolvimento sustentável em suas cidades.

Para a Open University (2016b), “cidades são centros de inovação e criatividade, mas também enfrentam grandes desafios tais como acelerada urbanização, mudanças climáticas e crescentes aumentos de pressão por serviços públicos como transportes e saúde".

A resposta a esses desafios e também oportunidades é tornar-se uma cidade inteligente, porém existem diversas definições para cidade inteligente. 
Cidade Inteligente e Cidadãos Participativos - Uma Proposta de Transformação Contínua da Cidade Através da Ação Colaborativa dos Cidadãos

Nesse sentido, considera que se tornar uma cidade inteligente, então, é um processo pelo qual as cidades usam tecnologias inteligentes e abordagens inovadoras para enfrentar os seus desafios, para se tornarem mais resilientes e habitáveis.

\section{Uma proposta para desenvolvimento colaborativo e os cidadãos de cidades inteligentes}

A pesquisa objetiva sugerir uma metodologia colaborativa de avaliação do grau de inteligência de uma cidade e auxiliar na priorização de projetos e programas públicos, assim como de iniciativas privadas, visando um processo contínuo de transformação do estágio atual de uma cidade em um contexto mais inteligente.

Para alcançar esse objetivo seguiu o processo descrito a seguir.

1) Elaborar lista de possíveis critérios para cidades inteligentes;

2) Sugerir relacionamento entre os critérios e as múltiplas inteligências propostas por Gardner;

3) Elaborar formulário on-line para pesquisa de opinião sobre os critérios mais relevantes;

4) Analisar os resultados da pesquisa; e

5) Sugerir metodologia de avaliação cidadã e colaborativa para tornar cidades mais inteligentes.

\subsection{Lista de critérios inicialmente sugerida}

A primeira etapa consistiu em elaborar uma listagem com possíveis critérios exigidos para considerar uma cidade como inteligente (Quadro 01).

Quadro 01: Possíveis critérios para classificar uma cidade como sendo inteligente

\begin{tabular}{|c|c|}
\hline Critério & Descrição \\
\hline Mobilidade Inteligente & $\begin{array}{l}\text { Facilidade de deslocamento e múltiplas opções de transporte público e privado } \\
\text { (individual e compartilhado) }\end{array}$ \\
\hline $\begin{array}{l}\text { Variedade de Manifestações } \\
\text { Culturais }\end{array}$ & Incentivo a atividades de grupos profissionais e amadores, pagas e gratuitas \\
\hline $\begin{array}{l}\text { Infraestrutura Digitalizada e } \\
\text { Conectada }\end{array}$ & $\begin{array}{l}\text { Modelos 3D de ruas e sistemas de água, esgoto, energia, etc com sensores inteligentes } \\
\text { para transmissão de dados }\end{array}$ \\
\hline Eficiências Energéticas & $\begin{array}{l}\text { Soluções coletivas e individuais para economia e/ou geração de energia, e redução } \\
\text { de emissões de carbono }\end{array}$ \\
\hline Desenvolvimento Sustentável & $\begin{array}{l}\text { Cada vez mais empresas focadas em atividades economicamente viáveis, socialmente } \\
\text { justas e ambientalmente responsáveis }\end{array}$ \\
\hline $\begin{array}{l}\text { Variedade de Manifestações } \\
\text { Artísticas }\end{array}$ & Incentivo a atividades de grupos profissionais e amadores, pagas e gratuitas \\
\hline $\begin{array}{l}\text { Conexões com Outras Cidades } \\
\text { e Países }\end{array}$ & Facilidade para os cidadãos interagirem com pessoas de outras cidades e outros países \\
\hline Convivência Inteligente & $\begin{array}{l}\text { Facilidade para trocar informações e interesses com outros cidadãos, do mesmo } \\
\text { bairro ou não, para viabilizar ações e atividades conjuntas }\end{array}$ \\
\hline $\begin{array}{l}\text { Economia Criativa e } \\
\text { Compartilhada }\end{array}$ & $\begin{array}{l}\text { Facilidade em desenvolver trabalhos criativos e ações compartilhadas com ou sem } \\
\text { fins de remuneração }\end{array}$ \\
\hline Sustentabilidade Colaborativa & Estímulo a ações sustentáveis individuais, familiares, em grupo e organizacionais \\
\hline Segurança Pública & Condições seguras para deslocamento, atividades ao ar livre, etc. \\
\hline $\begin{array}{l}\text { Facilidade para Manifestações } \\
\text { Cidadãs, Políticas e Religiosas }\end{array}$ & $\begin{array}{l}\text { Facilidade para grupos manifestarem ordeiramente suas opiniões coletivas, políticas } \\
\text { e religiosas }\end{array}$ \\
\hline
\end{tabular}

Fonte: Autor 


\subsection{Quadro sugerido de correlação entre os critérios e as múltiplas inteligências}

Na segunda etapa foi elaborado um quadro com as inteligências propostas por Gardner e se buscou relacionar os critérios sugeridos com essas inteligências (Quadro 02).

Quadro 02: Relações entre critérios de avaliação de cidades inteligentes e as inteligências do indivíduo

\begin{tabular}{|l|l|}
\hline Inteligência do Indivíduo & Inteligência da Cidade \\
\hline Linguística & Conexões com outras cidades e países \\
\hline Musical & Manifestação artística \\
\hline Lógico-matemática & Infraestrutura / Eficiência energética / Desenvolvimento sustentável \\
\hline Espacial & Mobilidade \\
\hline Corporal - cinestésica & Manifestação artística \\
\hline Intrapessoal & Conexões com outras cidades \\
\hline Interpessoal & Conexões entre os cidadãos / Economia Criativa e colaborativa \\
\hline Naturalista & Sustentabilidade \\
\hline Existencial & Segurança pública / Manifestação cidadã, cultural e religiosa \\
\hline
\end{tabular}

Fonte: Autor

\subsection{Formulário on-line para pesquisa de opinião}

$\mathrm{Na}$ terceira etapa foi confeccionado um formulário on-line para coletar as percepções de diferentes cidadãos com formações variadas.

O formulário se manterá funcional após a conclusão do presente trabalho e pode ser acessado através do endereço https://goo.gl/forms/W8bjZMAmEUuhyJ152.

$\mathrm{O}$ anexo I apresenta os questionamentos do formulário utilizado na pesquisa.

\subsection{Respostas ao formulário on-line}

A seguir, apresentam-se os resultados para os questionamentos do formulário.

4.4.1 Da lista abaixo escolha (apenas) as cinco características que julgar mais importantes para uma cidade ser considerada inteligente

Foram apresentados 12 critérios para que os entrevistados escolhessem as cinco principais características que, em suas opiniões, são importantes para uma cidade ser considerada inteligente (Figura 01).

Em 15 de outubro de 2016, 31 participantes haviam respondido ao formulário, resultado na distribuição apresentada no gráfico que segue.

Figura 01: Respostas para as 05 principais características de uma cidade inteligente pelos entrevistados

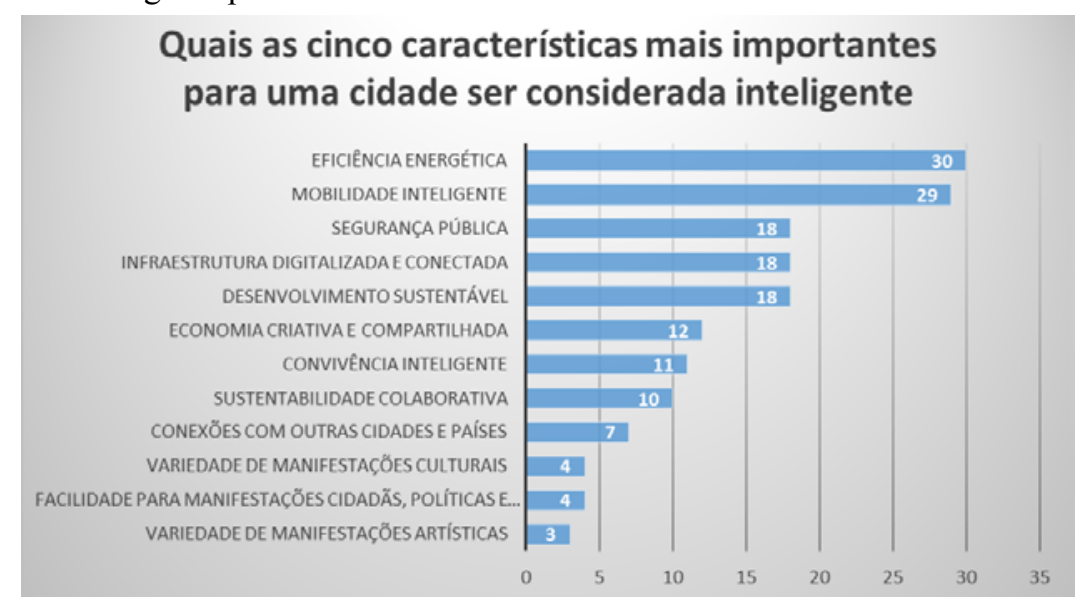

Fonte: Formulário de pesquisa on-line 
Observa-se que, para 30 participantes (96,8\%), o fator eficiência energética é fundamental e para 29 entrevistados $(93,5 \%)$ o fator mobilidade inteligente também. Esses dois formaram o primeiro grupo de prioridades para os entrevistados conforme se pode observar, inclusive graficamente.

O segundo grupo de critérios mais apontados, que foi objeto da escolha de 18 entrevistados $(58,1 \%)$ em todos os casos, correspondeu aos critérios segurança pública, infraestrutura digitalizada e conectada, e desenvolvimento sustentável.

Um terceiro grupo identificado contemplou os critérios economia criativa e compartilhada (escolhido por 12 participantes $-38,7 \%$ ), convivência inteligente (escolhido por 11 participantes - 35,5\%) e sustentabilidade colaborativa (escolhido por 10 participantes - 32,3\%).

Um grupo unitário se apresentou com o critério conexões com outras cidades e países, tendo sido escolhido por 07 participantes, o que representou $22,6 \%$ do total de entrevistados.

Finalmente, o último grupo incluiu os critérios Variedade de manifestações culturais e facilidade para manifestações cidadãs, políticas e religiosas (ambos escolhidos por 4 entrevistados - 12,9\%), e Variedade de manifestações artísticas (escolhido por 3 entrevistados -9,7\%).

Convém destacar que o critério infraestrutura digitalizada e conectada, que é de diferentes formas citado em todas as definições de cidades inteligentes identificadas pelo autor durante a pesquisa bibliográfica, não ficou posicionada no primeiro grupo, recebendo 18 escolhas, enquanto que a média de escolhas do primeiro grupo foi $291 \frac{1}{2}$. A percepção de sua importância para o grupo entrevistado atingiu o mesmo resultado que segurança pública e desenvolvimento sustentável.

Outro desempenho que chamou atenção do autor foi o critério conexões $\mathbf{c m}$ outras cidades e países ter obtido praticamente o dobro dos resultados das opções de manifestações culturais, cidadãs, políticas, religiosas e artísticas.

\subsubsection{Como você definiria uma cidade inteligente?}

Nesse quesito, 19 entrevistados responderam essa questão aberta, que apresentou o seguinte resultado (Quadro 03).

Quadro 03: Respostas para: Como você definiria uma cidade inteligente?

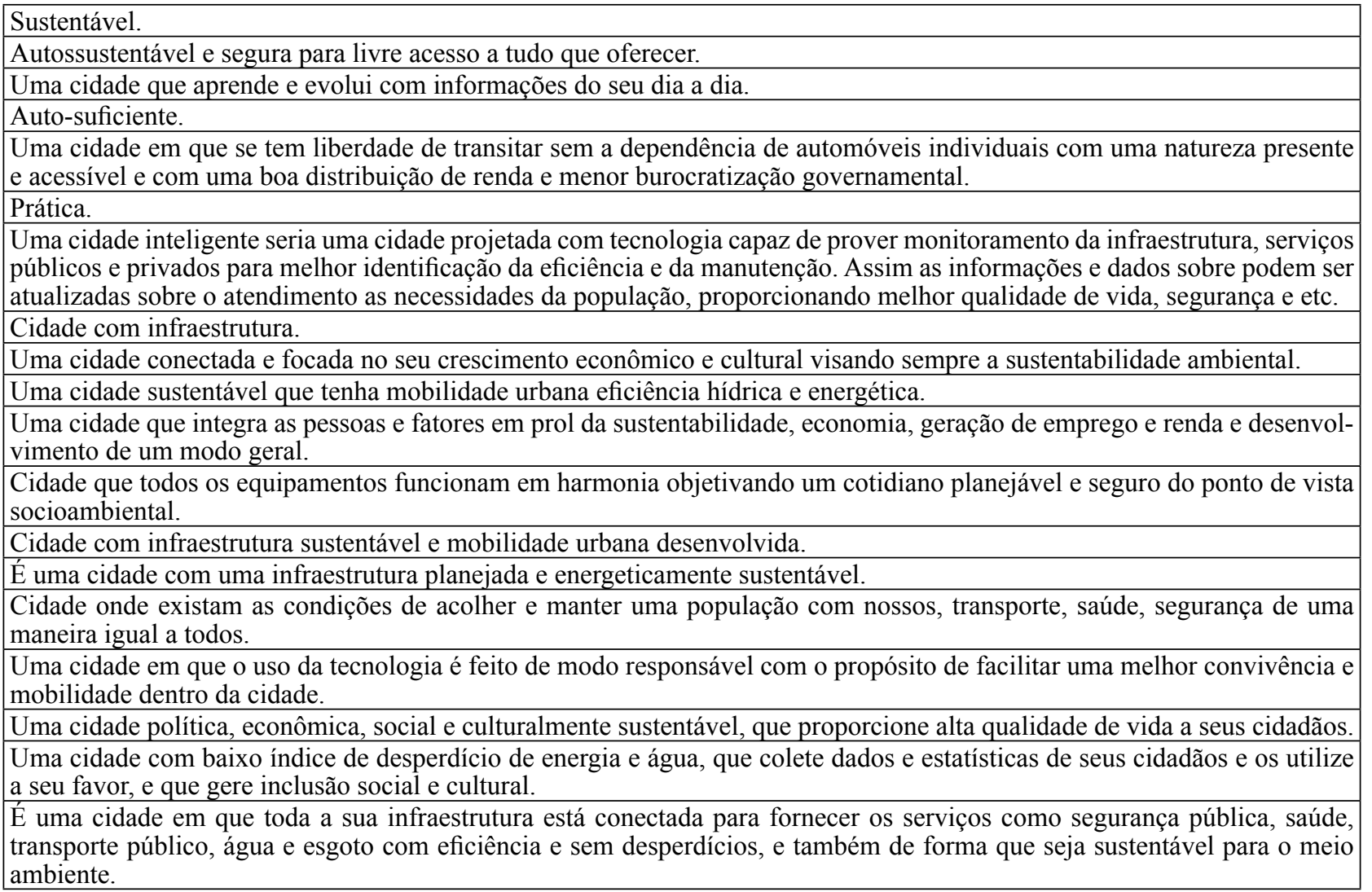

Fonte: Formulário de pesquisa on-line 
Observa-se nas respostas dos participantes que para 12 deles as definições abordam mais de um critério (ou seus aspectos relacionados), tais como (grifo do autor do artigo):

$\checkmark$ "Autossustentável e segura para livre acesso a tudo que oferecer";

$\checkmark$ "Uma cidade em que se tem liberdade de transitar sem a dependência de automóveis individuais com uma natureza presente e acessivel e com uma boa distribuição de renda e menor burocratização governamental";

$\checkmark$ "Uma cidade inteligente seria uma cidade projetada com tecnologia capaz de prover monitoramento da infraestrutura, serviços públicos e privados para melhor identificação da eficiência e da manutenção. Assim as informações e dados sobre podem ser atualizadas sobre o atendimento as necessidades da população, proporcionando melhor qualidade de vida, segurança e etc.";

$\checkmark$ "Uma cidade sustentável que tenha mobilidade urbana eficiência hídrica e energética";

$\checkmark$ "Uma cidade que integra as pessoas e fatores em prol da sustentabilidade, economia, geração de emprego e renda e desenvolvimento de um modo geral";

$\checkmark$ "Cidade com infraestrutura sustentável e mobilidade urbana desenvolvida";

$\checkmark$ "Uma cidade que integra as pessoas e fatores em prol da sustentabilidade, economia, geração de emprego e renda e desenvolvimento de um modo geral";

$\checkmark$ "Cidade onde tem as condições de acolher e manter uma população com nossos, transporte, saúde, segurança de uma maneira igual a todos";

$\checkmark$ "Uma cidade em que o uso da tecnologia é feito de modo responsável com o propósito de facilitar uma melhor convivência e mobilidade dentro da cidade";

$\checkmark$ "Uma cidade política, econômica, sócio e culturalmente sustentável, que proporcione alta qualidade de vida a seus cidadãos";

$\checkmark$ "Uma cidade com baixo índice de desperdício de energia e água. Que colete dados e estatísticas de seus cidadãos e os utilize a seu favor e que gere inclusão social e cultural";

$\checkmark$ "É uma cidade em que toda a sua infraestrutura está conectada para fornecer os serviços como seguranca publica, saúde, transporte público, água e esgoto com eficiência e sem desperdícios e também de forma que seja sustentável para o meio ambiente".

$\checkmark$ Nas definições espontâneas, apenas em cinco se observa uma referência intensa ao uso das tecnologias de comunicação e informação como meio de melhoria do desempenho de outros critérios.

$\checkmark$ "Uma cidade que aprende e evolui com informações do seu dia a dia";

$\checkmark$ "Uma cidade inteligente seria uma cidade projetada com tecnologia capaz de prover monitoramento da infraestrutura, serviços públicos e privados para melhor identificação da eficiência e da manutenção. Assim as informações e dados sobre podem ser atualizadas sobre o atendimento as necessidades da população, proporcionando melhor qualidade de vida, segurança e etc.";

$\checkmark$ "Uma cidade conectada e focada no seu crescimento econômico e cultural visando sempre a sustentabilidade ambiental";

$\checkmark$ "Uma cidade em que o uso da tecnologia é feito de modo responsável com o propósito de facilitar uma melhor convivência e mobilidade dentro da cidade";

$\checkmark$ "É uma cidade em que toda a sua infraestrutura está conectada para fornecer os serviços como seguranca publica, saúde, transporte público, água e esgoto com eficiência e sem desperdícios e também de forma que seja sustentável para o meio ambiente".

4.4.3 Dessa mesma lista de critérios, qual o item mais importante para uma cidade inteligente?

Solicitando aos entrevistados que selecionassem apenas uma opção na lista de critérios, obteve-se o resultado que segue (Quadro 04). 
Quadro 04: Respostas para: Qual o item mais importante para uma cidade inteligente?

\begin{tabular}{|l|c|c|}
\hline \multicolumn{1}{|c|}{ Critério } & $\mathbf{N}^{\mathbf{0}}$ de Escolhas & \% sobre o Total \\
\hline Mobilidade inteligente & 10 & $32,26 \%$ \\
\hline Desenvolvimento sustentável & 8 & $25,81 \%$ \\
\hline Infraestrutura digitalizada e conectada & 6 & $19,35 \%$ \\
\hline Segurança pública & 2 & $6,45 \%$ \\
\hline Convivência inteligente & 2 & $6,45 \%$ \\
\hline Economia criativa e colaborativa & 1 & $3,23 \%$ \\
\hline Sustentabilidade colaborativa & 1 & $3,23 \%$ \\
\hline Eficiência energética & 1 & $3,23 \%$ \\
\hline
\end{tabular}

Fonte: Formulário de pesquisa on-line.

Importante observar que enquanto o critério mobilidade inteligente se manteve como um dos principais na opinião dos entrevistados, a eficiência energética foi descolada significativamente, na condição de uma única escolha pelos participantes.

Um segundo grupo manteve os critérios desenvolvimento sustentável e infraestrutura digitalizada com elevada quantidade de escolhas pelos entrevistados.

O terceiro grupo com baixa quantidade de escolha reuniu os critérios segurança pública, convivência inteligente, economia criativa e colaborativa, sustentabilidade colaborativa e eficiência energética.

Um último grupo de critérios não pontou. o mesmo era composto por quatro critérios (1) variedade de manifestações artísticas, (2) facilidade para manifestações cidadãs, políticas e religiosas, (3) variedade de manifestações culturais e (4) conexões com outras cidades e países. esse grupo contemplou exatamente os mesmos critérios que se posicionaram nos últimos lugares no primeiro questionamento no qual os participantes tiveram a liberdade de escolher 5 critérios como os mais importantes.

\subsubsection{Qual outro item deveria ser considerado para termos uma cidade inteligente?}

Esse questionamento foi respondido por 21 participantes, conforme descrito no quadro que segue (Quadro 05).

Quadro 05: Respostas para: Qual outro item deveria ser considerado para termos uma cidade inteligente?

\begin{tabular}{|l|}
\hline Mobilidade inteligente \\
\hline Mobilidade inteligente \\
\hline Maior participação política \\
\hline Sistema educacional integrado \\
\hline Fácil mobilidade \\
\hline Mobilidade \\
\hline Melhor distribuição do capital e da renda \\
\hline Deixar a cidade preparada para o crescimento no longo prazo, tipo 50 anos \\
\hline Esportes \\
\hline Desenvolvimento sustentável \\
\hline Smart grid: Rede de distribuição inteligente \\
\hline Integração da população com o governo \\
\hline Mobilidade Inteligente \\
\hline Escolas modernas e integradas \\
\hline Acessibilidade \\
\hline Tratar o ecossistema com responsabilidade \\
\hline Segurança \\
\hline Escolas excelentes \\
\hline Respeito \\
\hline Inteligência artificial \\
\hline O desenvolvimento sustentável \\
\hline
\end{tabular}

Fonte: Formulário de pesquisa on-line 
Convém destacar que a pergunta buscou alcançar dos participantes, sugestões adicionais aos critérios inicialmente propostos.

Por tanto, a seguir se apresenta um quadro revisado excluindo sugestões já citadas nas questões anteriores (Quadro 06).

Do seguinte quadro também foram excluídos os elementos considerados componentes dos critérios citados inicialmente:

- Smart Grid: considerado como um elemento de eficiência energética;

- Melhor distribuição do capital e da renda: considerado incluso no critério Desenvolvimento Sustentável;

- Tratar o ecossistema com responsabilidade: considerado incluso no critério sustentabilidade colaborativa;

- Segurança: considerado no critério segurança pública;

- Acessibilidade: considerado no critério mobilidade inteligente;

- Maior participação política e integração da população com o governo: considerado no critério Facilidade para manifestações cidadãs, políticas e religiosas;

- Respeito: considerado no critério convivência inteligente

Quadro 06: Quadro revisado com as sugestões de acréscimos de critérios

\begin{tabular}{|l|}
\hline Sistema educacional integrado \\
\hline Deixar a cidade preparada para o crescimento no longo prazo, tipo 50 anos \\
\hline Esportes \\
\hline Escolas modernas e integradas \\
\hline Escolas excelentes \\
\hline Inteligência artificial \\
\hline
\end{tabular}

Fonte: Autor

Observa-se no quadro revisado que o tema educação foi o mais citado (3 participantes).

\subsubsection{Qual sua formação ou atividade profissional?}

Do total de 31 participantes, 29 responderam informando sua formação ou atividade profissional, conforme quadro 07 .

Quadro 07: Respostas para: Qual sua formação ou atividade profissional?

\begin{tabular}{|l|}
\hline Gerente de projetos \\
\hline Gerente de projetos \\
\hline Gerente de projetos \\
\hline Gerente de projetos \\
\hline Gerente de projetos \\
\hline Gerente de projetos \\
\hline Bancária \\
\hline Bancária \\
\hline Bacharel em Computação \\
\hline Especialista, Empresário \\
\hline Nivel superior \\
\hline Tecnologia da informação \\
\hline Engenharia \\
\hline Arquitetura e urbanismo \\
\hline Administração \\
\hline Tecnologia da informação \\
\hline
\end{tabular}


Cidade Inteligente e Cidadãos Participativos - Uma Proposta de Transformação Contínua da Cidade Através da Ação Colaborativa dos Cidadãos

\begin{tabular}{|l|}
\hline Engenheiro \\
\hline Estudante de Arquitetura e urbanismo \\
\hline Assessora administrativa \\
\hline Engenheiro eletricista \\
\hline Arquitetura e urbanismo \\
\hline Engenheiro civil \\
\hline Geógrafo, coordenador de projetos \\
\hline Eng. civil \\
\hline Pós-graduado \\
\hline Estudante \\
\hline MBA em GP e RH. Bacharel em ciência da computação \\
\hline Gestor de TI, gerente de projetos \\
\hline Estudante de Engenharia civil \\
\hline
\end{tabular}

Fonte: Formulário de pesquisa online

Os participantes da pesquisa possuíram, conforme quadro 07, diferentes formações e atuações profissionais. Além disso, também houve a participação de estudantes de graduação.

\subsection{Proposta de metodologia de avaliação cidadã e colaborativa para tornar cidades mais inteligentes}

Em função da pesquisa bibliográfica e da pesquisa descrita anteriormente, chegou-se a uma proposição de metodologia de avaliação cidadã e colaborativa para tornar as cidades mais inteligentes.

A metodologia objetiva incentivar uma ativa participação dos cidadãos, auxiliando os gestores públicos e de organizações privadas (com ou sem fins lucrativos), em um processo contínuo de transformação da cidade. Para torná-la mais inteligente, em especial no entendimento dos próprios cidadãos, apresentam-se os seguintes passos:

1. Definir lista de critérios de inteligências da cidade para avaliação dos cidadãos

Baseado na lista preliminar de critérios sugerida no presente trabalho (ver item 4.1), adicionando-se sugestões de participantes, inclusive dos cidadãos, o gestor municipal poderá determinar de forma colaborativa um conjunto de critérios a ser empregado na entrevista da pesquisa de opinião com as partes interessadas. Recomenda-se que na presente lista sejam considerados os 17 Objetivos de Desenvolvimento Sustentável (ODS) da Organização das Nações Unidas (ONU), que implicitamente serão considerados nas metas a serem alcançadas em todos os projetos e, assim, de forma inequívoca estarão presentes em todas as decisões.

2. Realizar pesquisa de opinião junto aos cidadãos sobre os critérios prioritários

Utilizando os recursos da tecnologia da informação, ou mesmo através de pesquisas presenciais convencionais, coletar as opiniões do cidadão quanto aos critérios mais importantes que devem ser considerados para tornar a cidade mais inteligente.

3. Tabulação das opiniões dos cidadãos

Processando as respostas dos cidadãos, classificar os critérios em ordem democrática de importância definida pelos participantes.

4. Identifica os critérios considerados prioritários pelos cidadãos

A partir da tabulação, identificar os critérios mais importantes segundo os próprios cidadãos, para servir como filtro para seleção e priorização de projetos.

5. Elaboração de lista de projetos para todos os critérios

Em um novo processo participativo, coletar sugestões de projetos e organizá-los por critérios de inteligência da cidade. 


\section{Seleção e priorização dos projetos}

Empregando técnicas apropriadas, selecionar os projetos mais alinhados estrategicamente com as prioridades definidas pela própria população, identificando uma possível relação de causa e efeito, definindo assim também uma proposta de sequência de execução.

7. Modelagem do termo de abertura dos projetos selecionados

Para os projetos selecionados, elaborar um termo de abertura com as informações preliminares críticas de cada projeto.

8. Proposta de sequência de execução dos projetos

Em função da análise de relação de causa e efeito (passo 6) e da estimativa de prazo do projeto constante do termo de abertura (passo 7), criar uma previsão de cronograma do portfólio de projetos resultantes do processo de sugestão, seleção e priorização colaborativo.

9. Apresentação e votação dos projetos pelos cidadãos

Expor os projetos selecionados e suas sequências propostas para coletar de forma democrática a corresponsabilidade dos cidadãos quanto ao portfólio proposto.

10. Execução dos projetos acordados com os cidadãos

Realizar, após um detalhamento do plano e adequação orçamentária aos recursos públicos e de parceiros disponíveis, os projetos contratados em colaboração com a sociedade.

11. Aplicar processo colaborativo de monitoramento e controle

Empregando aplicativos para smartphone com base de dados em nuvem, é possível viabilizar não apenas o acompanhamento das ações de cada projeto, como também permitir a gestão e pontuação contínua dos cidadãos, no que se refere à percepção da qualidade da entrega ocorrida e até mesmo de eventuais mudanças de importância ou prioridade para os projetos.

12. Estabelecer indicadores de desempenho do projeto e do portfólio

Empregando as boas práticas de gerenciamento de projetos e portfólios (PMI, 2017) e definindo os indicadores mais adequados conforme a análise ambiental específica de cada cidade e comunidade demandante.

\section{Considerações finais}

Observou-se no desenvolvimento do presente trabalho que são diversos os entendimentos sobre o conceito de cidades inteligentes. Acredita-se que isso é coerente com o fato de que o ser humano possuiu diferentes critérios de inteligência (inteligências múltiplas), de forma que um agregado de seres humanos, como uma cidade, deve apresentar também múltiplas inteligências, ou múltiplos critérios de avaliação de suas inteligências.

Não se percebeu dificuldade em correlacionar as múltiplas inteligências individuais com diferentes aspectos de inteligência de uma cidade, inclusive aspectos empregados em distintas definições.

O emprego de tecnologias da informação, como o formulário on-line, mostrou-se extremamente útil, prático e bem distribuído, uma vez que pode ser acessado através de computadores (desktop e laptop), smartphones e tablets.

O público participante da pesquisa denotou um elevado entendimento dos conceitos relacionados às perguntas apresentadas, porém observa-se que é um conjunto de pessoas que também possuem elevado grau de formação acadêmica.

A metodologia apresentada, em primeira análise, mostra-se de implementação simples, capaz de alto grau de participação pelos cidadãos, com razoável velocidade de obtenção de proposta de portfólio de projetos para melhoria da cidade na ótica dos seus cidadãos.

Como sugestão de trabalhos futuros propõe-se:

- Aplicá-la em diferentes grupos, tais como: comunidades, conjuntos habitacionais, associações de bairros, cidades, etc;

- Desenvolver aplicativos para dispositivos móveis que possam ser usados para coletar a opinião dos cidadãos, tabular e apresentar as prioridades definidas de forma colaborativa; 
Cidade Inteligente e Cidadãos Participativos - Uma Proposta de Transformação Contínua da Cidade Através da Ação Colaborativa dos Cidadãos

- Propor um modelo de canvas para auxiliar na organização, proposição, seleção e priorização dos projetos;

- Realizar outras simulações com diferentes grupos de cidadãos, homogêneos, heterogêneos, com diferentes realidades étnicas, culturais, sociais, educacionais e econômicas.

\title{
Referências
}

ALVES, Ubiratan Silva. Inteligências na Educação: percepção dos alunos e relações com a escola. 2001. 161 f. Dissertação (Mestrado em Psicologia da Educação) - Programa de Pós-Graduação da Faculdade de Educação da Universidade de São Paulo, 2001.

EUROPEAN COMISSION. Digital Single Market: policy: smart cities, 2015. Disponível em: <https://ec.europa.eu/ digital-single-market/en/smart-cities>. Acesso em: 30 ago. 2016.

GARDNER, Howard. Estruturas da mente: a Teoria das Múltiplas Inteligências. Porto Alegre: Artes Médicas, 1994.

INTELLIGENT COMMUNITY FORUM - IFC. Disponível em: $<$ http://www.intelligentcommunity.org/> Acesso em: 15 out. 2016

KOMININOS, Nicos. Intelligent cities and globalisation of innovation networks. London: Routledge, 2008

LINDSKOG, Helena. Smart Communities Initiatives. Disponível em: <https://www.researchgate.net/ publication/228371789_Smart_communities_initiatives>. Acesso em: 15 out. 2016.

MATIAS, Marcia Athayde. Relação entre características empreendedoras e múltiplas inteligências: um estudo com contadores de Minas Gerais. 2010. 123 f. Tese (Doutorado em Controladoria e Contabilidade) - Faculdade de Economia, Administração e Contabilidade, Universidade de São Paulo, São Paulo, 2010. Disponível em: <http://www. teses.usp.br/teses/disponiveis/12/12136/tde-27082010-102333/>. Acesso em 1 ago. 2016.

NICOLLIER, Valerie. Nos rastros da inteligência naturalista: novas teorias cognitivas aplicadas à educação ambiental. 2005. 236 f. (Mestrado em Desenvolvimento Regional e Meio Ambiente) - Universidade Estadual de Santa Cruz, Ilhéus, 2005.

OPEN UNIVERSITY. Life in a smart city. Disponível em: < https://www.futurelearn.com/courses/smart-cities/5/ steps/121635>. Acesso em: 12 out. 2016a.

OPEN UNIVERSITY. What is a smart city? Disponível em: <https://www.futurelearn.com/courses/smart-cities/5/ steps/121636>..Acesso em: 15 out. 2016b.

PROJECT MANAGEMENT INSTITUTE (PMI). Um Guia do Conhecimento em Gerenciamento de Projetos GUIA PMBOK. 6. ed. Pennsylvania: PMI Sobre o autor

\section{Sobre o autor}

\author{
Alexsandro Amarante \\ Engenheiro Civil - Universidade Federal do Ceará. Mestre em Engenharia de Produção - Universidade Federal de Santa \\ Catarina. Professor e Coordenador de Cursos de Pós-Graduação MBA em Gerenciamento de Projetos e MBA em Gestão \\ de Cidades Inteligentes da Escola de Tecnologia da Universidade de Fortaleza - Unifor.
}




\section{ANEXO I - Formulário de pesquisa dos critérios exigidos para uma cidade inteligente}

\section{Cidade Inteligente - Exigências}

Pesquisa sobre quais fatores são mais importantes para uma cidade ser considerada inteligente

Da lista abaixo escolha (apenas) as cinco características que julgar mais importantes para uma cidade ser considerada inteligente:

[ ] Mobilidade Inteligente (facilidade de deslocamento e múltiplas opções de transporte público e privado (individual e compartilhado)

[ ] Variedade de Manifestações Culturais (incentivo a atividades de grupos profissionais e amadores, pagas e gratuitas)

[ ] Infraestrutura Digitalizada e Conectada (modelos 3D de ruas e sistemas de água, esgoto, energia, etc com sensores inteligentes para transmissão de dados)

[ ] Eficiência Energética (soluções coletivas e individuais para economia e/ou geração de energia, e redução de emissões de carbono)

[ ] Desenvolvimento Sustentável (cada vez mais empresas focadas em atividades economicamente viáveis, socialmente justas e ambientalmente responsáveis)

[ ] Variedade de Manifestações Artísticas (incentivo a atividades de grupos profissionais e amadores, pagas e gratuitas)

[ ] Conexões com Outras Cidades e Países (facilidade para os cidadãos interagirem com pessoas de outras cidades e outros países)

[ ] Convivência Inteligente (facilidade para trocar informações e interesses com outros cidadãos, do mesmo bairro ou não para viabilizar ações e atividades conjuntas)

[ ] Economia Criativa e Compartilhada (facilidade em desenvolver trabalhos criativos e ações compartilhadas com ou sem fins de remuneração)

[ ] Sustentabilidade Colaborativa (estímulo a ações sustentáveis individuais, familiares, em grupo e organizacionais)

[ ] Segurança Pública (condições seguras para deslocamento, atividades ao ar livre etc.)

[ ] Facilidade para Manifestações Cidadãs, Políticas e Religiosas (facilidade para grupos manifestarem ordeiramente suas opiniões coletivas, políticas e religiosas)

Como você definiria uma cidade inteligente?

Dessa mesma lista qual o item mais importante para uma cidade inteligente?

( ) Mobilidade Inteligente

( ) Variedade de Manifestações Culturais

( ) Infraestrutura Digitalizada e Conectada

( ) Eficiência Energética

( ) Desenvolvimento Sustentável

( ) Variedade de Manifestações Artísticas

( ) Conexões com Outras Cidades e Países 
Cidade Inteligente e Cidadãos Participativos - Uma Proposta de Transformação Contínua da Cidade Através da Ação Colaborativa dos Cidadãos

( ) Convivência Inteligente

( ) Economia Criativa e Colaborativa

( ) Sustentabilidade Colaborativa

( ) Segurança Pública

( ) Facilidade para Manifestações Cidadãs, Políticas e Religiosas

Qual outro item deveria ser considerado para termos uma cidade inteligente?

Qual sua formação ou atividade profissional?

Recebido em: 27/01/2017

Avaliado em: 28/05/2018

Aceito em: 28/05/2018 